\title{
Violence Against Women: A Gender Issue And Role Of Educational Institutions At Secondary Level In District Mardan
}

\author{
Muhammad Idris \\ Department of Education \\ Abdul Wali Khan University Mardan \\ Khalid Iqbal \\ Department of Elementary \& Secondary Education \\ Government of Khyber Pakhtunkhwa \\ Saqib Shehzad \\ Department of Education \\ Abdul Wali Khan University Mardan
}

\begin{abstract}
Domestic violence, war against woman and gender inequality is the gender issues faced by both males and females. It is the phenomenon that not only dividend the home but also cultural, social, economic and political implications on human life. Education always plays a lucrative role in the eradication of social evils. This study was aimed to explore the root causes of domestic violence and gender inequality and the role of educational institutions in eradicating domestic violence. 200 teachers from government secondary schools were interviewed in which there were 120 male and 80 female. Informal interview was used as in-depth information was needed for the phenomenon. Modified analytical induction approach was applied according to the nature of the study. Themes and patterns were drawn from the interviews and conclusion was made. The study revealed that gender discrimination existed in the field of education, health, cultural, political, social and economic spheres of life in society. The study found out that male-dominant society, poverty, illiteracy, child issue, culture issue, morality, and psychological feelings were the factors responsible for domestic violence. Recommendations to eradicate this problem were made in the light of research findings.
\end{abstract}

Keywords: Gender, Domestic Violence, Inequality, Role of Education.

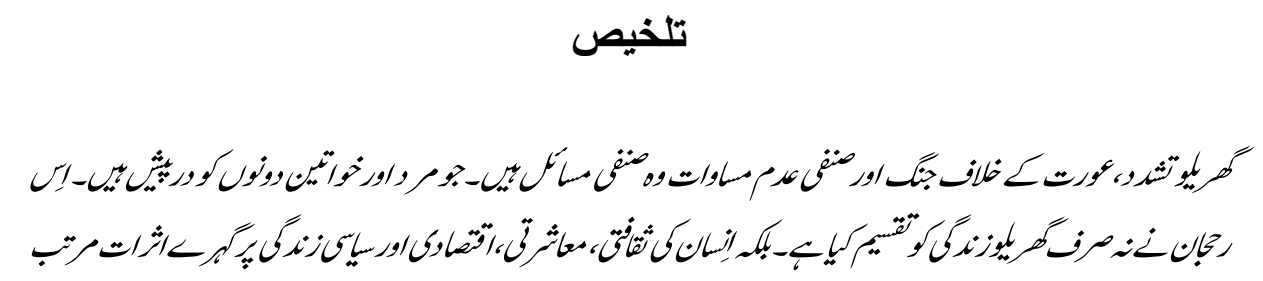




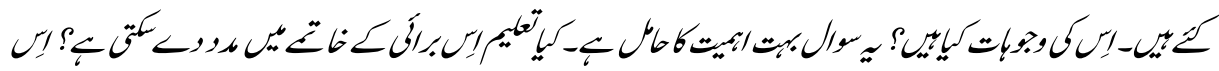

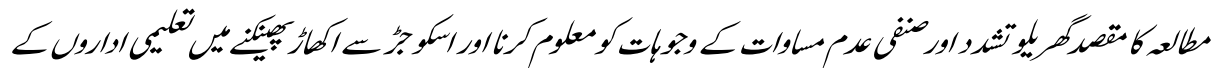

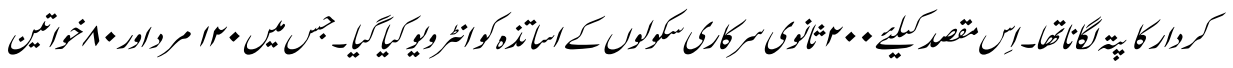

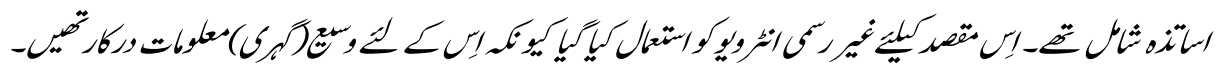

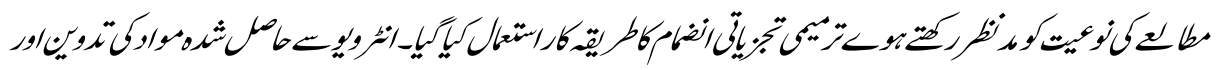

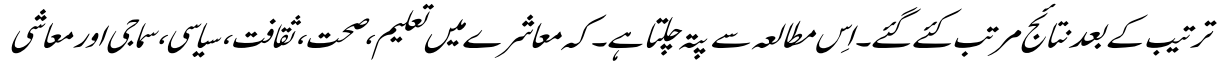

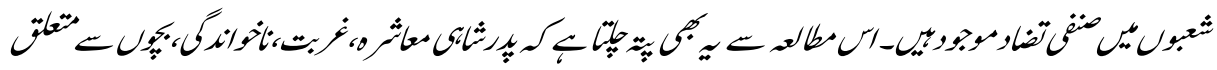

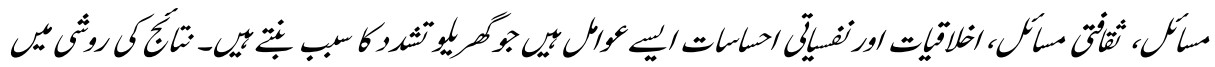

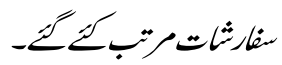

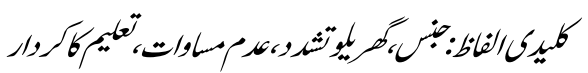

\section{Introduction}

Violence against woman is convoluted issue having diverse dimension to comprehend. A meticulous organized, synchronized and persistent effort is needed to combat domestic violence. It is an important social matter of concern that demanded extraordinary attention because it has ruthless social, emotional, psychological and physical consequences (Ali \& Gavino, 2008). It is considered the most prevalent and invasive problem including physical, psychological, sexual and economic abuses whose prevalence is regardless of age, space, culture and race. Gender violence is committed at various levels .i.e. family, community and national having diverse appearances. In a report of United Nation Millennium, Goal (2011) stressed and advocated for "promoting gender equality" but the situation remained same and the target is far away to be accomplished, particularly in south Asia. Domestic violence, gender inequality, gender disparity and war against the women are the terms use for the issue. WHO (1999) expressed in its press release that the modern society failed to recognize the role of house-wife and it's devaluing is increasing. Various forms of the abuses like physical, psychological, economic, disrespect, breaking of trust, separation, and mauling are there in the form of domestic violence. A survey conducted by WHO (2009) whose findings revealed that physical or sexual abuse by the husband or partner was $15 \%$ to $71 \%$ while $4 \%$ to $12 \%$ were abused during their pregnancy. The survey also reported that about 5,000 women lost their lives every year in the name of honor killing around the world. UNIFEM (2011) expresses, "Violence against woman is the breach of human rights. These are taken in the form of psychosomatic, corporeal and also geographical. It has no limits; it is beyond the race, cost, chronological age, culture and wealth. These violent 
actions are taken place everywhere in houses, in streets, workplaces, fields, farms and even in educational institutions. It happens on refugees' camps and in war and calamities. These are of various forms ranging from domestic and sexual threat to harmful practices, i.e. honor murders, pregnancy abuse and other brutal actions".

\section{Gender Differences and Domestic Violence}

Gender differences are considered the real distinction between male and female in terms of sense or capability or any other distinctive characteristic of behavior. Generally, gender disparity is meant when there is gap between male and female or favoritism shown between male and female in any walk of life. Woman is the threaten character in this burning issue and found everywhere and in different forms. Coomaraswamy (2005) stated that there are various types of violence which are persisted in social setting and commune i.e. burning of bride, murder for prestige, different kinds of harassment such as street and forced sex, childhood marriage etc. All these threats and violence are not independently exit. It is related to political and social environment, technological revolutions; emergence of new trends in social setup and many other factors linked to it.

Domestic violence or threats are actions that are based on daunt frightful actions which terrorize, make pressurize, scare and other coercive behaviors that makes other hurt or injured physically or mentally. The most common term used for this kind of violence is domestic violence. Some time it is also called family or partner violence. Various organizations, states agencies use the terms according to their own. But at the end interpretation is the same; abuse of power and woman is victim. According to Zaman (2007), violence in home is often observed committed by man against woman. This is also known as domestic violence, possibly underreported offense against woman and next to the rape case which is always overlooked by the community. According to Pakeeza (2015), it is a social problem and considered it very hard to comprehend because of various reasons. Various researches all over the world show that it is social issue and needed exceptional and distinctive focus because of the attachment of social, emotional, physical and psychological penalty and cost. Sometimes domestic violence is considered abusive behavior which is most often conduct by an individual in relation to control other person. It is a kind of insulting and offensive actions taken to establish power or gain power to control the other family member. The abusive behavior started delicately, propelled and pushed way the survivor from the family, as time passed it heat up and appear harmful. According to the concluding remarks of Khan et al. (2014), it is existed in every culture, religion and society but third world country suffering more than developed countries. It is observed that controlling behavior of husband and mother-inlaw is also very important factor. The educated and professional women are facing the same violence as the uneducated and poor. 
According to World Bank (2003), there is common acceptance in the developed commune that the development plan and action failed to address the discrimination between male and female which has serious cost repercussion. Gender inequality or discrimination has multiple directions and related to the various field of life. It included social, economical, demographical and political fields. The heaviest cost is observed in the field of production due to lack of involvement in formal work, education and economical activities (Sajid, 2014). According to WEF (2010), the basic areas of gender discrimination are:

Educational field: It related to the attainment of basic and higher education level or other learning academies.

Economic field: It is related with the participation and providing opportunities for woman in the field of economy i.e. in salaries, level of participation and access to skilled employment.

Political field: It is concerned with the representation of woman in decision making process and all other such public and political activities.

Health: $\quad$ Health is another important area where women are ignored.

For holistic development, gender equality is necessary. It has social, political and economic benefits. WHO (2012) reported that greater the gender equality, the greater will be the productivity. It causes improvement in the outcomes and makes the institution healthy and representative (Sajid, 2014). According to Word Bank (2012), if the disparity between male and female is reduced, the productivity level can be increased. For example, education has impact upon the growth (Klasen, 2002) and access to equal opportunity in economic and working increases growth (Klasen \& Lammana, 2008). This will ensure to get their talent and skill employed in productivity (World Bank, 2012).Victimization of the women is called gender violence. According to UNDP (1995), in all culture and working groups, woman and girls are subjected to victims and violence because of the gender discrimination. Corporal and verbal mugs, emotional and sexual torture, sterilization and forced abortion are the forms of violence and victimization of the woman. According to Beijing Declaration (1995), reports objectives of the achievements of equality, peace and progress has been obstructed by the violence against woman. It says that any corporal, psychological, sexual victimization are violence against woman. Acts like forceful deprivation of liberty and other such coercive forces in public or private are considered as violence against woman. WHO (2009) reported that there are different forms of gender violence such as emotional abuse, physical abuse, sexual abuse and other types of threats i.e. dowry threats, intimate partner, sex and forced labor threats are the forms of gender violence.

\section{Causes of Violence}

There are two types of violence in the term of occurrence not causes i.e., self-tortured and other tortured. The causes may be different in each and every case but apparently, the 
actions show only the occurrence of the violence. There are cases in which the women victimize themselves which are in the forms of self-burning, self-poisoning or other harmful actions done by the bride. Other causes are depression, low self-esteem, infertility of woman for children and suicide or homicide actions. There are causes of victimization of woman conducted by others. It may include killings for honor, forced marriage against the wishes of woman, forced pregnancy, and woman trafficking. Other abuses such as Satti i.e. burning alive, sex related cases like different types of rapes in one or other forms persist in society as well.

Chaudhry (2004) categories causes of violence into general and specific as:

General Causes: The general causes included poverty, lack of education in whole family, especially ignorance of Islamic values, frustration of wife or husband due to various internal or external factors cause of such violence. Dowries, demanding of separate homes, mother in law or sister in law attitudes are causes of victimization. Sometimes culture, customs and tradition create space for violence.

Specific Causes: Specific causes related to causes or events that lead toward the gender violence are the suspected or illicit relation of the husband or wife, second marriage of the husband and lack of understanding between wife and husband. Other causes are the reciprocal based marriage, specific health problems, drug addiction of husband and child issues.

\section{The Perpetrator}

Feeling of anxiety and glumness are most often arises due to tussle and quarrels with husband or other relative of in-laws. Taket et al. (2003) have the opinion that abuses are mostly occurred on their own. Controlling the power of other is the main issue between them; most often the male partner is considered the culprit. Who are responsible for the creation of these things, the question is of millions importance.

Zaman (2007) suggested following valuable elements that may be the perpetrators of all these burning issues:

Intrapersonal: The intrapersonal factors responsible for these issues are anger, power controlling, intimated fear, hostility, feelings of low self-esteem, stress tolerance, minimization, anxiety and despair.

Interpersonal: Factors like jealousy, suspiciousness of partner, weak communication between the partner, verbal aggression, belligerent and negative attitude towards the woman are the interpersonal aspects that create the issues. 
Environmental: The environment is also responsible for this problem as a tradition. Sometimes violence in family is already existed, the use of various kinds of drugs or addiction, unemployment etc.

Psychological Factors: Many psychological factors involved in the eruption of violence i.e. isolation, separation, non-socialization, alcohol drinking, dependency, aggressiveness in behavior and emotional control.

Historical and situational factors: Abused childhood by parents, harsh and ruthless spousal behavior, arrests, availability and frequent use of weapons, divorce cases, child dispute, hostile attitudes and other such situations create violence.

\section{Pakistani Society and Gender Problems}

Pakistan possesses plural culture having diversification in norms and values which don't set well the existing laws. There are force marriages, silence towards woman abuse, reluctance to raise private matters in public, rape etc (Rashid, 2016). According to UNISON (2008), research exposed that in Europe about 50\% of the women employees in the European Union Countries are the victims of sex harassment. If the civilized world is suffering with this issue with so heated intensity then what will be the position of the third world. The answer is clear; the more intensity will be expected.

According to the Global Gender Gap Report (2013), it is the dilemma of the third world countries and Pakistan is one of them which are suffering from gender discrimination and inequality. It is on the top of the list and rank on $135^{\text {th }}$ out of 136 states for this issue. Saghir et al. (2013) in his concluding remarks stated that women in Pakistan are mostly victimizing in the rural area and low class in home, at farms and outside the home. He believes that women should be respected according to the spirit of Islam and their due status should be given to them in all walk of the life. Fikree \& Bhatti (1999) expressed that women faced ill-treatment regularly due the social and cultural tradition of Pakistan. It has been reported that woman in Pakistan faced huge sufferings against the women violence. The main factor is the continuous repression of the rights of women which spoil their social position (Bettencourt, 2000).

\section{Role of Education}

Learning and education starts from cradle and ends to the grave. When Black Box (Cognitive learning) opens or Tabula Rasa (Behaviorist learning) starts working, learning process begins. Education is the right of every human being since born. Although a child learns from his environment informally yet formal education is the significant contributor in his growth and development. A systematic education provides and creates 
opportunities for children to be developed intellectually, physically, emotionally, aesthetically and socially fitted. Above all education is a complex process of formatting and developing the human personality to all its perfection. Education and learning promote social equity, empathy, commiseration and human rights and responsibilities. It promotes harmony among the cultures, environmental, personal care and peace, and to ward off the war and aggression (Reynaldo, 2011; University of Peace, 2011). Education is the powerful changing behavioral tool. Gender issues are also created by the behavior and have to be resolved by the behavior.

The success of student is depending upon the performance of a teacher. The aim is to know about the growth and learning performance of the students to plan strategies for the students' achievement targets (GaDOE, 2012). In the light of the importance of the role of education, every successive government gives priority to education system in Pakistan and takes steps to improve and provide more opportunity to its people (Zaman, 2007). Every nation beyond its status tries to improve its education system. But unluckily, due to some specific religion and other theological aspirations, the gender disparity aspects are given little attention so far, especially in Muslim states. This survey study was aimed to understand the burning issue of gender violence or gender discrimination in one form or in other. Woman of the day is being considered as victim by the society especially in the third world countries. The problem is significant because it not only destroys the domestic peace but has far-reaching effect on the life of humanity.

\section{Methodology}

\section{Participants, Data Collection and Analysis}

It is a qualitative and phenomenological study in which qualitative and phenomenological methods were used. As a result, the researcher gets themselves aware of the participant's points of view and developed assumption on observation rather than pre made hypothesis (Merriam, 2001; Palys, 2003). The main focus of this kind of study is to investigate things or events from the lens of veteran and experience people. In-depth and inside prospect of the phenomenon was needed to be understood that why this approach was applied (Conrad, 1987). The aim is to gain insight into the phenomena and provide plenty of stuff for description of lived practices and experiences. The main objective of the current study under investigation was to make aware the educators about the gender issues i.e. domestic violence, gender inequality and war against woman. It also objects to explore the root causes of gender inequality, gender violence and role of educational institution regarding domestic violence.

The study was conducted in district Mardan, one of the central districts of Khyber Pakhtunkhwa, Pakistan. All the teachers working at government secondary and higher 
secondary levels in Mardan district constituted the population of the study. According to the Annual Statistics of Government Schools issued by Elementary and Secondary Education Department Khyber Pakhtunkhwa, there were total 185 secondary and higher secondary schools in Mardan district in which 101 schools were for boys and 84 for girls. In these schools, there were total 2855 teachers in which 1836 males and 1019 females (EMIS, 2015).

Interviews, observation and reviews of the documents are the main source of data collection the qualitative study (Creswell, 2009; Locke, Silverman, \& Spirduso, 2010). Plays (2003 said that interview facilitate and assist the researcher to understand the phenomena, events, and experiences of the participants. According to Merriam (2001) interview is the most suitable instruments to obtain in-depth and rich information about the phenomenon. In the current study, an informal interview was used as instrument for data collection as in-depth information was needed for the research study. 200 government schools' teachers were interviewed in which 120 were male and 80 were female teachers. Interviews were conducted by two interviewers. From the male respondents, the data was collected by the researcher himself and from the female teachers; data was collected by an expert female teacher as per the instruction provided by the principal researcher. Modified analytical induction approach was applied according to the nature of the study. The collection of data began from a specific question and identified all the causes of this phenomenon in the context of investigation. The iterative process of data collection has been applied to be focused on specific outcomes. The collected data was organized, categorized, codified for searching and locating commonalities, relationship and theoretical constructs (Mills et al., 2010). So, accordingly themes and patterns were drawn from the interviews and codified separately by both the interviewers. At the end of refining process of the raw data, the findings of the both interviewers were unified and the conclusions were drawn.

\section{Findings}

The purpose of the study was to explore and understand the domestic violence and role of education in eradicating the domestic violence and gender discrimination. The study was descriptive in nature as modified analytical induction approach was applied and interviews were conducted to seek the responses of the participants regarding gender discrimination, domestic violence and role of education in its eradication. The findings of the study can be demarcated into areas i.e., Areas of discrimination, domestic violence and their causes; and Role of the education.

\section{Areas of Discrimination}

The main findings of the study were categories into the following areas: 
Education: Both of the respondents i.e. male and female agreed that there is discrimination or difference in the educational field.

Cultural: It was found that in culture especially in Pakistani culture women are devalued. In Khyber Pakhtunkhwa, the situation is more intense than other province of Pakistan.

Political: Differences are observed in the political field and women are given very little opportunities and importance in politics.

Social: Most of the respondents opined that women are given very little opportunities in the social activities. Sometimes, they differed in the social field and they are considered non-social especially in the rural areas.

Economical: Gender inequality is seen in the field of economics as well. Being considering a weak figure, they are provided or permitted very little opportunities to take part in the economic activities.

\section{Domestic Violence and Causes}

The study found that the domestic violence as different forms. It may be in the shape of physical beating, threaten, emotional torture, different types of banes, sexual harassment and assault in different places such as in workplaces, in educational institutions, even is streets. The study found out some factors that are responsible for the causes of gender or domestic violence which are:

The research revealed that in the male dominant society, male wants to be superior, control wife using force and if wife denied doing so, it leads to tussle. Most often in the joint family system, sometimes the relative in-laws trying to establish their dominancy by force that leads to the tussle in home. Poverty breeds strife, to get employment in Pakistan is big problem. Poverty leads to tension and tension leads to emotional disturbance and ultimately war in home begins. Tussle on dowries, demanding separate home by woman and poor health care issues related to poverty. So, economic problems are one of the factors in this issue. Low level of education among the masses is also one of the sources of violence in Pakistan. Lack of understanding, self-esteem problems are raised due to lack of understanding.

The study revealed that reciprocal based marriages, sometimes leads to violence and creates domestic violence. A sort of revenge erupted when situation aggrieved in one side then the second side automatically suffered one suffer other suffer. It was revealed from the interview that the illicit relations of man or woman become the source of violence. The husband or wife suspected of the illicit relations or disloyalty and betrayal of one another or the other person of the family suspected of these relations. According to the research, odd cases of such relations sometimes proved true and it caused the base of violence or threat. Morality of the people has been going down, the home culture which 
was once safe for woman now replacing in strife and tiffs. According to the respondents' views, the technological revolution is one of the great sources of this disturbance. For example, the mobile technology and dish television degrade the morality of the new generation. Misuses of mobile create many problems in homes, and some of television channels broadcast illegal contents that ultimately hit the morality of the society.

The study investigated some psychological and health problems that lead to violence. Anger management of one or both of the partners in homes, drug abuse or eating of addictive things, poor communication between the partners, and emotional control are the factors that cause such violence. The study also investigated that there are issues such as child issue becoming the source of victimization. The family members want that someone should the heir of the parent but due to health or some other problems, woman is unable to give birth to the babies and it becomes the source of victimization in home. It was investigated that some cultural issues like second marriage of the husband, joint family system, restriction of woman in homes and such other things lead to the issue. Love affair in Pakistani culture (illegal affairs) in the Muslim society and especially in Pakhtun culture is considered sin and most of breeds' violence. The study revealed that role of media is not positive. Due to lack of education and non-socialization especially in rural area, it affects badly the young generation. Mostly they present the foreign culture and in some cases, it is directly against the cultural norms which cause violence in society.

\section{Role of Education}

It was found that as far as formal system of education is concerned at secondary level there is neither separate nor integrated approach applied in the curriculum for gender education. However, at university level, there is gender education as subject or discipline started. But at lower level i.e., secondary or higher secondary level, the curriculum is looking silence. There is very slice of gender rights which is the part of the religion or culture taught to the students. The education department not conducting any seminar, workshop or provides any such practical training to the teachers about the gender education. If, by chance they did so only the high ups attend the workshops or seminars, get the remuneration and that's all.

Teachers are not interested or have no sufficient time to teach them about the gender equality personally because of lack of interest or being over burden. They teach them only the topics that are related to the assessment process i.e. annual exam etc. Teachers opined that education can play better role in the removal of gender related problems. There are so many problems that are directly or indirectly related to gender issue. Education is the behavioral change and moral, emotional, economic problems can be addressed through education if proper focus may be given to the gender education especially at secondary level. 
Figure 1 Shows the Summary of the Findings

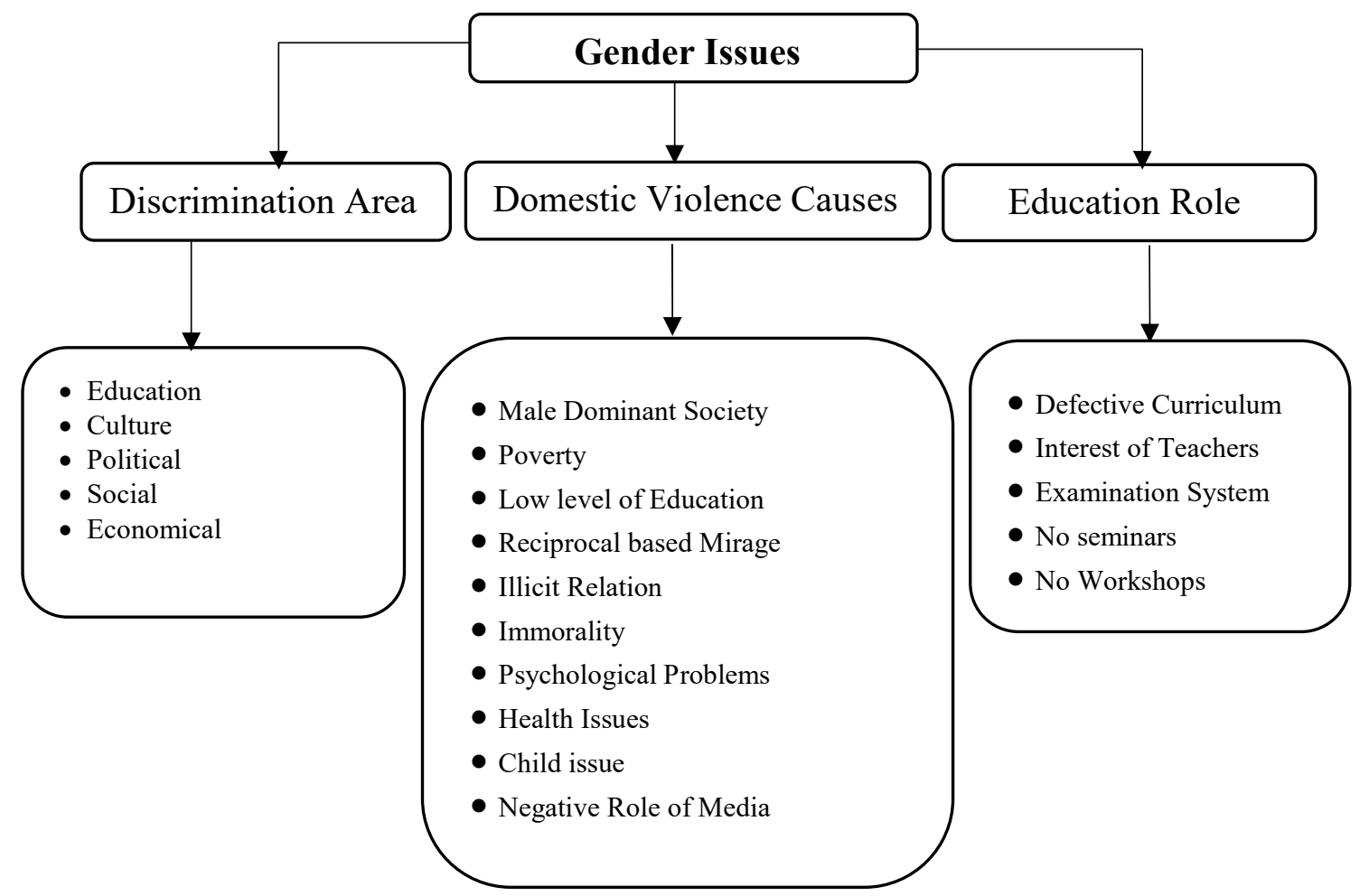

Gender issue is not an isolated issue; it has a cause and effects relation. It is deep rooted in culture, it has social and economic roots, and it has psychological roots. It is rooted in health; it is rooted in the hierarchy of the family. Progress towards gender equality plays an important and lucrative role to meet global goals and to eradicate poverty and to eliminate hunger and malnutrition. However, in Pakistan the gender equality that is unequal access to the productive resources, including land services and input, training and access to the market and other institution fettered the realization of the woman's human and productive prospective (FAO, 2017). According to Bunch (2004), security of women should be the basic concern in public and private sphere of life because it is the integral part of sustaining the security of the whole population. It was found that in each case, the responsibility is different. However, culture norms, weak position of woman, literacy rate, non-socialization, religion and societal set up were the main factors that lead to discrimination. According to Nasrullah \& Bhatti (2012), despite of the efforts, Pakistan has faced challenges in respect of gender inequalities and there is ample gap existed between male and female. This inequality can be seen in employment opportunities, paid work, health etc. It is deep rooted in Pakistani society. Culturally, right from the birth, Pakistani women are discriminated and it is the life time issue with women. 
Unequal power relation between man and woman is the root cause of the gender based violence. There are factors at the family level, community level, society level and individual level that contribute to raise the probability of violence. Gender based violence has far-reaching effects and extended beyond the personal level to the family and ultimately to whole society. The most effective thing is the strong social response needed for common understanding of the nature and cause of gender violence. It can be settled from all sides via contribution of various sectors and the involvement of whole community (Human Rights, 2003). Gender discrimination, gender violence or domestic violence is a serious issue and it should be solved. Different organizations public or private, national and international, regional and local are trying to calm down the intensity of the problem. The study revealed the elements and causes that originate the issue. All over the world consensus on the one point that women are the victims and man is the perpetrator of this issue. Some questions arise here:

Is it natural occurrence? Is it war against woman? Is woman should be set free of the issue? What is the cultural role and what it does say? What is the role of the religion? Is there religion imposed any sanction on woman? Can we blame both are responsible? How to nip this evil in bud? Education is the most powerful tool of changing the behavior. The gender issue whether it is restricted to discrimination or victimization and use of violence of woman is related to the behavior of the individual. The role of education in Pakistan is not up to the mark. Right up to the secondary level, the students are totally unaware of the issue. Neither in the curriculum there is any stress on the matters related to the issue, nor the teachers focusing the gender issue. The teachers are interested only in those areas of the curriculum that is the part of the annual examination because the government is interested only in passing of the students not in the quality of education. The teachers are always focusing on the marks and grading of the students because their performance is always measured in the terms of passing ratio not of changing the behavior of the learners. So, a strong and quality system of education is needed to developed understating and comprehension of the problem and make out ways and means to solve the problems.

\section{Recommendations}

Based on findings and conclusions, the following recommendations were made:

1. It is necessary for educational institutions to apply strategies to prevent and respond to domestic violence through educational process. Institutions need to actively promote gender equality and non-violent domestic culture. For this purpose, at each level, curriculum should be reviewed and restructured in the light of strategies to eradicate gender inequality, discrimination and violence.

2. Educational Institutions are required to play an indispensable role in eradicating gender discrimination and violence through ensuring awareness among teachers, 
students, parents and other personnel. The students may play a potential role as agents of change which provide one of the greatest hopes for achieving the social transformation necessary to root up gender based violence and discrimination.

3. Media should play encouraging and constructive role in the eradication of violence against women by adopting guidelines which ensure sensitive coverage of the issue and avoid the perpetuation of stereotypes.

4. Comprehensive, practicable and effective laws and policies should be formulated to prevent gender discrimination and violence. Specific, enforceable and accountable regulations and measures should be ensured to prevent gender-based violence; to expedite the launching of new law and policies on preventing gender-based violence; to review, improve and augment the enforcement of existing laws and policies, and to conduct monitoring and evaluation of this enforcement; to promote good practices and the multi-sector intervention model; to modify positively the attitude and behaviors of perpetrators through education and community services.

5. Recognize the important role and experiences of civil society organizations, especially women's NGOs, and help publicize their good practices and their participation as equal partners of multi-sector collaboration to discourage violence against women.

\section{References}

Ali, P. \& Gavino, M. (2008). Violence against Women in Pakistan: A Framework for Analysis, Journal of Pakistan Medical Association, vol.58:4, pp.198-203.

Beijing Declaration. (1995). Fourth World Conference on Women, http://www.un.org /womenwatch/daw/beijing/platform/declar.htm.

Bettencourt, A. (2000). Violence against Women in Pakistan. Human Rights Advocacy Clinic; Litigation Report Spring 2000 www.du.edu/intl/humanrights/ violencepkstn.pdf

Bunch, C. (2003/04).A Feminist Human Rights Lens on Human Security. Centre for Women's Global Leadership. Retrieved from www.cwgl.rutgers.edu.

Chaudhry, A.G. (2004). Violence against Women - A Case Study. International Journal of Agriculture \& Biology, vol.6:4, pp.1560-8530 http://www.ijab.org.

Conrad, P. (1987). The Experience of Illness: Recent and New Directions. Research in the Sociology of Health Care, vol.6, pp.1-31.

Coomaraswamy, R. (2005). The Varied Contours of Violence against Women in South Asia. Retrieved from: http:// www.unifem.org. 
EMIS (2015). Government of KPK, Elementary \& Secondary Education Department, retrieved on 25th June 2017, http://www. kpese.gov.pk/home/ view.cfm? MenuID

Fikree F. \& Bhatti L. I. (1999). Domestic Violence and Health of Pakistani Women. International J Gynaecol Obstet, vol.65, pp.195-201.

Fitzgerald, L.F., Gelfand, M.J. \& Drasgow, F. (1995). Measuring Sexual Harassment: Theoretical and Psychometric Advances. Basic and Applied Social Psychology, vol.17, pp.425-445.

Fitzgerald, L.F., Swan, S. \& Magley, V. (1997). But was it really sexual harassment? Legal Behavioral and Psychological Definitions of the Workplace Victimization of Women. In W. O'Donohue (Ed.), Sexual Harassment: Theory, Research and Treatment. New York: Allyn \& Bacona. pp.5-28.

FAO. (2017). Regional Gender Strategy and Action Plan 2017-2019 for Asia and the Pacific. Food and Agriculture organization (FAO): Bangkok.

GaDOE (2012). Georgia Department of Education Student Learning Objectives Manual: Student Learning Objectives Operations Manual. Georgia Department of Education, www.GaDOE.org.

Global Gender Gap Report, World Economic Forum (2013). http://www3.weforum.org /docs/WEF_GenderGap_Report_2013.pdf.

Human Rights (2003).Causes and Effects of Gender-Based Violence. Minnesota Advocates for Human Rights; available from: http://www.stopvaw.org.

Hussain, S. Basit, H. \& Javaid, A. (2014). Computational Analysis of Stereotypes as Cause of Gender Inequality: A Study of Universities of South Punjab, Pakistan. Pakistan Journal of Social Sciences, vol.34:2, pp.473-484.

Khan, A. J. et al. (2014). Lifetime Prevalence of Emotional/Psychological Abuse among Qualified Female Healthcare Providers. Sociology Mind, vol.4, pp.174-182. http://dx.doi.org /10.4236/sm.2014.42017.

Klasen, S. (2002). Low Schooling for Girls, Slower Growth for All? World Bank Economic Review, vol.16, pp.345-373.

Klasen, S. \& Lamanna, F. (2008). The Impact of Gender Inequality in Education and Employment on Economic Growth in Developing Countries: Updates and 
Extensions, EUDN Working Paper 2008-10 (Namur, Belgium: European Development Research Network).

Locke, L. F., Silverman, S. J. \& Spriduso, W.W. (2010). Reading and Understanding Research, $3^{\text {rd }}$ Ed. Thousand Oaks: Sage Publications.

Merriam, S. (2001). Qualitative Research and Case Study Applications in Education. San Francisco: Jossey-Bass.

Mills, A. J., et al (2010). Thematic Analysis. Encyclopedia of Case Study Research. Sage Publications, Inc. Thousand Oaks, CA: SAGE Publications, Inc.

Muazzam, N. \& Junaid A. B. (2012). Gender Inequalities and Poor Health Outcomes in Pakistan: A Need of Priority for the National Health Research Agenda. Journal of the College of Physicians and Surgeons Pakistan, vol.22:5, pp.273-274.

Pakeeza, S. (2015). Domestic Violence Laws and Practices in Pakistan: VFAST Transactions on Education and Social Sciences, vol.6:1, pp.17-20.

Palys, T. (2003). Research Decisions: Quantitative and Qualitative Perspectives (3 ${ }^{\text {rd }}$ ed.). Canada: Nelson.

Rashid, A. (2016). Pakistan, Woman Right and the Clergy- A Case Study of the Punjab Protection Against Violence Act 2016. Retrieved on Jan 15, 2016 from: www.usefpakistan.org/alumni/public/alumniconfernce/press/Amna-Rashidpdf.

Reynaldo R. TY. (2011). Human Rights, Conflict Transformation, and Peace Building: The State, Ngos, Social Movements, and Civil Society- The Struggle for Power, Social Justice and Social Change. Ph.D Dissertation; Northern Illinois University Dekalb, Illinois.

Saghir, A. Tabassum, H., Amir, M., Arshad, S.,Cheema, A. \& Cheema, S. (2013). Gender and Violence: A Rising Issue: The Journal of Animal \& Plant Sciences, vol.21:3, pp.632-634.

Sajid, S. (2014). Political Economy of Gender Equality: Case Study of Pakistan. International Journal of Gender and Women's Studies, vol.2:2, p.310.

Taket, A., Nurse, J., Smith, K., Watson, J., Shakespeare, J., Lavis, V. \& Feder, G. (2003). Routinely Asking Women about Domestic Violence in Health Settings. British Medical Journal, 327, 673. http://dx.doi.org/10.1136/bmj.327.7416.673. 
University of Peace. (2011). Peace Education: Theory and Practice. Retrieved on April 19, 2011 from: http://classroom.upeace.org/course/search.php?search= dimensions

UNDP (1995). Human Development Report 1995. New York: Oxford University Press.

UNIFEM (2011). Violence against Women, UN Commission for Women. Online available on www.unifem.org

UNICEF (2000). Domestic Violence against Women and Girls. Florence, Innocenti Digest http://www.unicef-irc.org/publications/pdf/digest6e.pdf.

UNISON (2008). Harassment at Work. UNISON. http://www.unison.org.uk/acrobat/ 17763.pdf, retrieved on 11September, 2012.

United Nations (UN). The Millennium Development Goals Report (2011). New York: United Nations; retrieved from: http:/www.un.org/millennium goals/11MDG\%20 Report_EN.pdf.

WHO (1999). The World Health Report 1999: Making a Difference. World Health Organization, 1211 Geneva 27, Switzerland.

WHO (2009). Violence against Women, Fact Sheet N 239. November 2009. Retrieved from: http:// www.who.int/mediacentre/factsheets

World Bank (2003). Turkey-Reforming the Health Sector for Improved Access and Efficiency. World Bank, Human Development Sector Unit: Washington, D.C.

World Economic Forum (WEF) (2010). Global Gender Gap Report. Retrieved from: http://www.weforum.org/issues/global-gender-gap.

Dr. Muhammad Idris is an Assistant Professor in the Department of Education, Abdul Wali Khan University Mardan.

Dr. Khalid Iqbal is Subject Specialist in the Department of E \& SE, KP.

Dr. Saqib Shehzad is an Associate Professor in the Department of Education, Abdul Wali Khan University Mardan. 